\title{
Predictors of Service Satisfaction Among Clients Receiving Antiretroviral Therapy Services at Public Hospitals in Eastern Ethiopia
}

\author{
Taye Mekonnen' \\ Yadeta Dessie ${ }^{2}$ \\ Biftu Geda $\mathbb{D}^{3}$ \\ Zelalem Bekele (iD ${ }^{3}$ \\ Genanaw Atnafe ${ }^{3}$ \\ Lemma Getacher (ID) ${ }^{4}$ \\ 'Department of Public Health Emergency, \\ Harari Regional Health Bureau, Harar, \\ Ethiopia; ${ }^{2}$ School of Public Health, \\ College of Health and Medical Sciences, \\ Haramaya University, Harar, Ethiopia; \\ ${ }^{3}$ Department of Nursing and Midwifery, \\ College of Health and Medical Sciences, \\ Haramaya University, Harar, Ethiopia; \\ ${ }^{4}$ Department of Public Health, College of \\ Health Sciences, Institute of Medicine and \\ Health Science, Debre Berhan University, \\ Debre Berhan, Ethiopia
}

Background: The issue of service satisfaction with antiretroviral therapy services needs more attention as it indicates the outcome of quality health services. Although different studies have been conducted on client satisfaction in different countries, there is limited evidence on the major predictors of client satisfaction with ART services in Ethiopia.

Objective: To assess the predictors of service satisfaction among clients receiving antiretroviral therapy services at a public hospital in Harar Town, Eastern Ethiopia.

Methods: A hospital-based cross-sectional study design was employed among 413 antiretroviral therapy clients from February to March 2018. The data were cleaned and entered into EpiData version 3.1 and exported to SPSS version 21 for analysis. A five-point Likert scale was used to assess client satisfaction with the ART services. Clients who scored $\geq 75 \%$ of the items were categorized as "satisfied" and those who scored $<75 \%$ of the items were categorized as "dissatisfied". Independent variables with a p-value of $\leq 0.25$ in the binary regression analysis were included in the multivariate logistic regression analysis to control confounding factors. Statistical significance was set at a p-value less than 0.05 .

Results: The overall client satisfaction with ART services was 76.9\% (95\% CI: 72.6, 80.6). Regarding the predictors, clients who were not attending formal education [(AOR $=3.7,95 \%$ CI: $1.75,8.12)]$ and primary education $[(\mathrm{AOR}=3.9,95 \% \mathrm{CI}: 1.66,9.32)]$, low wealth index $[(\mathrm{AOR}=2.8,95 \% \mathrm{CI}: 1.27,6.28)]$, longer duration of treatment [(AOR=2.7, 95\% CI: 1.46 , 5.5.20)], shorter waiting time $[(\mathrm{AOR}=5.4,95 \% \mathrm{CI}: 2.52,11.57)]$, disclosure of serostatus of HIV [(AOR $=3.7,95 \% \mathrm{CI}: 1.59,8.49)]$, seen by the same health care providers repeatedly [(AOR $=2.0,95 \% \mathrm{CI}: 1.06,3.82)]$, loss of medical records [(AOR=0.26, 95\% CI: 0.13,0.50)] and social supports $[(\mathrm{AOR}=2.3,95 \% \mathrm{CI}: 1.12,4.63)]$ were significantly associated with service satisfaction on antiretroviral therapy services.

Conclusion: Overall client satisfaction with ART services was relatively low in the study area. However, not attending formal and primary education, low wealth index, longer duration of treatment, shorter waiting time, disclosure of serostatus, seen by the same health care providers, loss of medical records, and social support were independent predictors of client satisfaction.

Keywords: antiretroviral therapy, client satisfaction, Ethiopia, Harar, public hospitals, predictors

\section{Introduction}

Client satisfaction can be defined as the personal evaluation of clients toward antiretroviral therapy (ART) services and the extent to which clients feel that their needs and expectations are being addressed by the service providers. The
Correspondence: Lemma Getacher Email lemmagetacher@gmail.com 
concept of client satisfaction is widely used to assess the quality of health care services. It has a multidimensional health care impact on ART services. There is a potential link between client satisfaction and compliance with treatment delays with individuals' satisfaction with ART services. Dissatisfaction can produce barriers and reduce the client's willingness to start or continue ART treatment. ${ }^{1-4}$

In both developed and developing countries, concerns regarding the client satisfaction were not an emerging phenomenon, because clients are the main stakeholders of health care organizations. However, satisfaction can be influenced by treatment process and treatment outcomes. Although it has been done through different activities to ensure client satisfaction, it is still very challenging to achieve universal client satisfaction, especially in developing countries such as Ethiopia. ${ }^{5,6}$

In the past many years, different health care researchers reported that the behaviors of clients were more satisfied with ART services adhere to their treatment, maintain follow-up schedules, build trust with health care providers, increase retention to care, and have good health outcomes compared to their counterparts. Thus, ensuring client satisfaction has a great impact on the quality of health care services and addressing client needs toward the services. ${ }^{5,7}$

Minimizing the emergence and transmission of drugresistant HIV is a critical aspect of the global response to antimicrobial resistance. The increasing prevalence of HIV drug resistance to commonly used antiretroviral drugs poses a threat to the HIV response, with the potential to fuel an increase in HIV incidence, mortality, and treatment costs. If it is not adequately addressed and ensured, clients will be dissatisfied with delivered ART services. ${ }^{8}$

Nowadays, the problem of client service dissatisfaction increases among the global countries and communities. Client dissatisfaction with ART services in Europe ranges from $35 \%$ to $42.2 \% .^{9,10}$ In Africa, client dissatisfaction with ART services ranges from $0.4 \%$ to $48 \%{ }^{11,12}$ whereas client dissatisfaction with ART services in Ethiopia ranges from $10.6 \%$ to $42.4 \% .^{13-15}$

Appropriate ART service provision must be considered to improve client satisfaction with ART services. Strengthening ART programs is important to promote the quality of life and quality of ART services. Moreover, protecting client satisfaction can enhance health care services by involving clients in decision-making and creating a good relationship with health care providers (HCPs). ${ }^{16}$ In addition, maintaining client satisfaction has a great impact on preventing treatment failure, drug resistance, and ultimately death of the client related to HIV/AIDS complications. ${ }^{3}$

One of the main objectives of Growth Transformation Plan II of the Ethiopian Federal Ministry of Health $(\mathrm{FMOH})$ is to create a good health care system that satisfies the community's health care through the fulfillment of the required inputs, such as by delivering quality, safety, accessibility, effectiveness and responsive health care services. Providing client-centered, equitable and highquality health care services for all results improvements in health and productivity of the society in general. ${ }^{17}$

Although different studies have been conducted on client satisfaction in different countries, there is limited evidence on client satisfaction with ART services in Ethiopia including the current study area. Besides, this study address factors which were not addressed by the previous studies. The impact of lost to medical cards and seen by the same health care providers on client's service satisfaction were not addressed well. Therefore, this study assessed the current magnitude of and predictors of client satisfaction with ART services and forwarded possible recommendations to improve client satisfaction with ART surviving at a public hospital in Harar Town, Eastern Ethiopia.

\section{Materials and Methods}

\section{Study Area, Period, and Design}

This study was conducted in Harar Town, which is located $526 \mathrm{~km}$ from Addis Ababa, the capital city of Ethiopia. Based on the 2008 enumeration, the total population of Harar Town was 183,415 . Of these, females accounted for $91,099(49.67 \%)$. Of the total population, 122, 057 (54\%) were urban dwellers.

In Harar, there are two public hospitals, two private general hospitals, 8 health centers, and 26 health posts. The two public hospitals had 5630 ever started on ART and 3435 currently on ART services. Based on the comprehensive health care services and ART services delivered, the data of this study were collected from two public hospitals (Hiwot Fana Specialized University Hospital (HFSUH) and Jugal Hospital (JH)).

In ART clinics, there were nine health care providers working in both hospitals. Four nurses and one doctor in HFSUH and three nurses and one doctor in JH. This study was conducted in Harar Town from February to March 2018 using a hospital-based cross-sectional study design. 


\section{Population}

The source population of the study was all ART clients attending public hospitals and the study population included all selected ART clients in public hospitals in Harar Town during the study period.

\section{Inclusion and Exclusion Criteria}

All ART clients who had follow-up during the study period and stayed on treatment for six or more months were included in the study. In contrast, ART clients with a terminal illness and those clients who were not willing to participate in the study were excluded from the study.

\section{Sample Size Determination}

The required sample size for the objective of the study was determined using a single population proportion formula through different assumptions such as the proportion of client satisfaction taken from a study conducted in West Wollega (57.6\%), ${ }^{14} \mathrm{za}_{/ 2}$ had a $95 \%$ confidence level of 1.96 , a margin of error of 0.05 , and a non-response rate of $10 \%$. Finally, the sample size was 413 .

\section{Sampling Technique and Procedures}

In Harar Town, there are two public hospitals. Both of them were selected purposively based on service provision to the public and delivery of comprehensive ART services. The total sample size was allocated proportionately for each hospital according to their client load of ART clinics. The average monthly trains of clients seen by a health care provider for 6 months before data collection in HFSUH were 1200 and in $\mathrm{JH}$ were 500.

The sampling frame of this study was taken from the list of clients selected from the ART register. The study participants in each hospital were selected using systematic sampling methods. The first client was selected by lottery method and the interval of the respondents for the interview was determined by dividing the average total number of clients per month receiving ART services in the two public hospitals from the previous month's data. In HFSUH $(\mathrm{k}=\mathrm{N} / \mathrm{n}, 1200$ / $266=5)$ and in $\mathrm{JH}(\mathrm{k}=\mathrm{N} / \mathrm{n}, 500 / 147=3)$. Then every fifth and third were selected from the two public hospitals, respectively, until the desired sample size of the study was achieved.

\section{Data Collection Methods Data Collection Instruments}

The data collection instruments were developed by reviewing different kinds of literature to increase the comparability of the findings and consistency. The different published articles were searched using varying search engines like Google, Google Scholar, Hinari, and PubMed. Data were collected using a pretested structured interviewer-administered questionnaire. The questionnaire contains sociodemographic characteristics, health facilities, and health care provider's related characteristics. The questionnaires were first developed in English and then translated to Amharic and Afan Oromo languages. ${ }^{11,14}$

\section{Data Collectors and Data Collection Procedures}

Four data collectors and two supervisors who were fluent both in Amharic and Afan Oromo and who did not work in the study sites were recruited for data collection. Two days ( 1 day theoretical and 1 day practical) of training about the objectives of the study and the procedure to be followed were given for data collectors and supervisors by the principal investigator before starting the actual data collection.

The data collection was conducted in an institutionbased exit interview by using a structured interviewer administered and pretested (on 5\% of the sample size) in Dilchora hospital before the actual data collection period to identify gaps in the designed questionnaires. Those ART clients who fulfilled the inclusion criteria and willing to participate were interviewed for an average duration of 30 minutes after they got the necessary services from the ART clinics of the hospital. On-site supervision was carried out during the whole period of data collected daily by the supervisors and the principal investigator.

\section{Variables}

The dependent variable of this study was the service satisfaction of clients with ART services. On the other hand, the independent variables were sociodemographic factors such as age, sex, educational status, marital status, occupational status, ethnicity, residence, and wealth index. The clientrelated factors were duration of ART treatment, disclosure, social support, maintained follow-up schedule, and willingness to visit and recommend for others. The health facility and health care provider-related factors were such as waiting time attended by the same health care providers, provision of supportive kits, health education, cleanness of waiting area and toilet, and loss of medical records.

\section{Operational Definitions Client Satisfaction}

Assessed by a five-point Likert scale ((1) very dissatisfied, (2) dissatisfied, (3) neutral, (4) satisfied, and (5) very 
satisfied) were used. All these five Likert scale measuring items were computed together to yield a maximum score of 25 (if all scores were scored very satisfied or 5 points) and a minimum score of 5 (if all scores were scored very dissatisfied or 1 point). Then after, the five-point Likert scale items were coded into two using a compute variable programme in the software during analysis. Accordingly, satisfied and very satisfied were recoded as "satisfied" whereas very dissatisfied, dissatisfied, and neutral were recoded as "dissatisfied". It was transformed into a percentage to give the satisfaction score from $0 \%$ to $100 \%{ }^{17}$

\section{Overall Client Satisfaction}

Clients who were satisfied with greater or equal to $75 \%$ of the items after a satisfaction question computed by the gathers were categorized under "satisfied" and those who were satisfied less than $75 \%$ of the items were categorized as "dissatisfied". 18

\section{Data Quality Control}

A structured interviewer-administered questionnaire was first prepared in English and translated to Amharic and Afan Oromo languages and then translated back to English by an independent language expert to ensure its consistency. The questionnaire was pretested on $5 \%$ of the sample size to ensure the validity of the tool. Then, a correction was made before the actual data collection. The principal investigator and supervisors were checked to ensure completeness and consistency of the information collected and immediate action was taken accordingly.

\section{Data Processing and Analysis}

The completed questionnaires were checked for completeness and consistency by the principal investigator and supervisors. The cleaned data were entered into Epi-Data version 3.02 and exported to SPSS version 21 for analysis. The descriptive data were presented using numerical summary measures, frequency tables, and figures.

Considering a $p$-value of $\leq 0.25$, variables were taken into the multivariate model to see the correlation between independent variables. Finally, the results of bivariate and multivariate logistic regression analyses were presented in a COR and AOR with $95 \%$ confidence intervals. P-value $\leq 0.05$ was considered statistically significant.

Multi-collinearity was checked to see the linear correlation among the independent variables using standard error. Variables with a standard error of $>2$ were dropped from the multivariate analysis. The model fitness was checked by Hosmer-Lemeshow's test which was found to be insignificant ( $\mathrm{p}$-value $=0.634)$ and the Omnibus test which was significant $(\mathrm{P}$-value $=0.001)$.

To observe the internal consistency of the items loaded on each factor, a reliability test was performed and the reliability coefficient (Cronbach's Alpha) greater than 0.7 was used as a cut-off point ( 0.847 in this study)

\section{Ethical Considerations}

Before conducting the study, the first ethical approval letter was obtained from Haramaya University Institutional Health Research Ethical Review Committee (IHRERC) and the official letter of cooperation was given to the two public hospital administrative offices. The reference letter of the approved letter was on 25 February 2018 and numbered with a Ref C/AC/R/D/ $907 / 18$. Informed, voluntary, written, and signed consent was obtained from the medical directors of the hospital. This study was conducted in accordance with the Declaration of Helsinki. ${ }^{27}$

After getting permission from the medical director of the hospital, it was given a clear description of the study title, duration, procedure, and possible risks and benefits of the study for each study participant. Hence, after an assured issue of confidentiality, voluntary, written, and signed informed consent was obtained from each selected study participant to confirm willingness to participate in the study.

For participants aged less than 18 years, informed, voluntary, written, and signed consent was obtained from their parents or guardians. Moreover, it was ensured and respected that all clients' have the right to selfdetermination and autonomy. Participation in this study was fully voluntary and clients can withdraw from the study at any time.

\section{Results}

\section{Sociodemographic Characteristics of Study Participants}

In this study, 413 interviews were secured in two public hospitals. However, only 407 questionnaires were completed and included in the analysis, making a response rate of $98 \%$. The mean $( \pm \mathrm{SD})$ age of the participants was $33.1( \pm 12.2)$ years. From the total study participants, nearly three-fifths, $233(57.2 \%)$ of the participants were female and $145(35.6 \%)$ were found within the age group of $31-40$ years (Table 1). 
Table I Sociodemographic Characteristics of Study Participants in Public Hospitals, Harar Town, Eastern Ethiopia, $2018(n=407)$

\begin{tabular}{|c|c|c|}
\hline Variables & Frequency & $\%$ \\
\hline \multicolumn{3}{|l|}{ Sex } \\
\hline Male & 174 & 42.8 \\
\hline Female & 233 & 57.2 \\
\hline \multicolumn{3}{|l|}{ Age (years) } \\
\hline$<20$ & 57 & 14.1 \\
\hline $20-30$ & 123 & 30.2 \\
\hline $31-40$ & 145 & 35.6 \\
\hline $4 I-50$ & 82 & 20.1 \\
\hline \multicolumn{3}{|l|}{ Religion } \\
\hline Muslim & $13 \mid$ & 32.2 \\
\hline Orthodox Tewahido & 203 & 49.9 \\
\hline Protestant & 54 & 13.3 \\
\hline Others* & 19 & 4.7 \\
\hline \multicolumn{3}{|l|}{ Ethnicity } \\
\hline Oromo & 152 & 37.2 \\
\hline Amhara & 159 & 39.1 \\
\hline Harari & 31 & 7.6 \\
\hline Tigray & 39 & 9.6 \\
\hline Gurage & 26 & 6.4 \\
\hline \multicolumn{3}{|l|}{ Marital status } \\
\hline Married & 196 & 48.2 \\
\hline Single & 102 & 25.1 \\
\hline Widowed/Divorced & 109 & 26.7 \\
\hline \multicolumn{3}{|l|}{ Residence } \\
\hline Urban & 384 & 94.3 \\
\hline Rural & 23 & 5.7 \\
\hline \multicolumn{3}{|l|}{ Educational status } \\
\hline Unable to read and write & 53 & 13 \\
\hline Read and write & 47 & 11.5 \\
\hline Primary education (I-8) & 176 & 43.2 \\
\hline Secondary education & 109 & 26.8 \\
\hline College and above & 22 & 5.4 \\
\hline \multicolumn{3}{|l|}{ Occupational status } \\
\hline Farmer & 13 & 3.2 \\
\hline Housewife & 90 & 22.1 \\
\hline Merchant & 82 & 20.1 \\
\hline Governmental organization & 52 & 11.5 \\
\hline Daily laborer & 121 & 30.1 \\
\hline Student & 49 & 12.0 \\
\hline \multicolumn{3}{|l|}{ Family size } \\
\hline$\leq 4$ & 366 & 89.9 \\
\hline$<4$ & 41 & 10.1 \\
\hline \multicolumn{3}{|l|}{ Wealth index } \\
\hline Low & 126 & 31.4 \\
\hline Middle & 132 & 32.4 \\
\hline High & 149 & 36.6 \\
\hline
\end{tabular}

Regarding religion, almost $50 \%$ of 203 (49.9\%) of the participants were Orthodox Tewahido Christian and 131 $(32.2 \%)$ of them were Muslims. Nearly forty percent 159 $(39.1 \%)$ of the participants were Amhara and more than one-third $145(35 \%)$ of them were Oromo by ethnicity. Nearly half 196 (48.2\%) of the participants were married. Related to residence, the majority of the participants were from urban 384 (94.3\%) (Table 1).

\section{Characteristics of Clients and Health Facilities}

Out of the total 407 study participants, more than half of the 290 (53.9\%) have stayed on treatment for less than 4 years. The majority of the participants $250(61.4 \%)$ received ART services less than 30 minutes from the hospital ART clinic. Nearly $90 \%$ of the study participants 363 (89.2\%) were disclosed their HIV/AIDS serostatus. From participants who had disclosed their serostatus, 260 $(63.9 \%)$ of them were disclosed to their parents (Table 2).

\section{Magnitude of Client Satisfaction with ART}

The magnitude of client satisfaction with antiretroviral therapy services was $76.9 \% \quad[(95 \% \quad \mathrm{CI}: 72.7,81.1)]$. Client satisfaction with the main items includes, with clinical triage $368(90.4 \%)$, courtesy and respect of health care providers 321 (78.9\%), location of ART clinics 341 $(83.8 \%)$, the explanation given by health care providers about ART treatment 374 (91.9\%), maintaining privacy $355(87.2 \%)$, relationship with health care providers 375 (92.1\%), counseling services 380 (93.4\%) and convenience in getting medical services $344(84.5 \%)$ were satisfied respectively. Whereas with the help fullness of medical record room staff, only 151 (37.1\%) of the clients were satisfied (Figure 1).

\section{Factors Associated with Client Satisfaction Among Clients Receiving ART Service}

Those variables with a $\mathrm{P}$-value $\leq$ of 0.25 in the bivariate analysis were entered into multivariate analysis using an enter method to identify the independent factors of client satisfaction. Clients who had not attended formal and completed primary education were 3.7 and 3.9 times $[(\mathrm{AOR}=3.7,95 \% \mathrm{CI}: 1.75,8.12)]$ and $[(\mathrm{AOR}=3.9,95 \%$ CI: $1.66,9.32)]$ more likely to be satisfied with antiretroviral therapy services compared to clients who had college 
Table 2 Medical Characteristics of the Study Participants in Public Hospitals, Harar Town, Eastern Ethiopia, 2018 ( $N=407)$

\begin{tabular}{|c|c|c|c|}
\hline Variable & & $\begin{array}{l}\text { Frequency } \\
\text { (N) }\end{array}$ & $\%$ \\
\hline Duration on treatment & $\begin{array}{l}\geq 4 \text { years } \\
<4 \text { years }\end{array}$ & $\begin{array}{l}188 \\
269\end{array}$ & $\begin{array}{l}3.9 \\
66.1\end{array}$ \\
\hline Waiting time & $\begin{array}{l}<30 \text { minutes } \\
\geq 30 \text { minutes }\end{array}$ & $\begin{array}{l}352 \\
55\end{array}$ & $\begin{array}{l}86.7 \\
13.3\end{array}$ \\
\hline Disclosure of serostatus & $\begin{array}{l}\text { Yes } \\
\text { No }\end{array}$ & $\begin{array}{l}363 \\
44\end{array}$ & $\begin{array}{l}89.2 \\
10.8\end{array}$ \\
\hline Seen by the same HCPS & $\begin{array}{l}\text { Yes } \\
\text { No }\end{array}$ & $\begin{array}{l}284 \\
123\end{array}$ & $\begin{array}{l}69.8 \\
30.2\end{array}$ \\
\hline Provision of supportive kits & $\begin{array}{l}\text { Yes } \\
\text { No }\end{array}$ & $\begin{array}{l}391 \\
16\end{array}$ & $\begin{array}{l}96.0 \\
4.0\end{array}$ \\
\hline $\begin{array}{l}\text { Perceived stigma and } \\
\text { discrimination }\end{array}$ & $\begin{array}{l}\text { Yes } \\
\text { No }\end{array}$ & $\begin{array}{l}33 \\
374\end{array}$ & $\begin{array}{l}8.2 \\
91.8\end{array}$ \\
\hline Home-based care services & $\begin{array}{l}\text { Yes } \\
\text { No }\end{array}$ & $\begin{array}{l}127 \\
280\end{array}$ & $\begin{array}{l}31.2 \\
68.8\end{array}$ \\
\hline Loss of medical records & $\begin{array}{l}\text { Yes } \\
\text { No }\end{array}$ & $\begin{array}{l}188 \\
227\end{array}$ & $\begin{array}{l}46.1 \\
53.9\end{array}$ \\
\hline Social supports & $\begin{array}{l}\text { Yes } \\
\text { No }\end{array}$ & $\begin{array}{l}268 \\
139\end{array}$ & $\begin{array}{l}65.8 \\
34.2\end{array}$ \\
\hline Health education & $\begin{array}{l}\text { Yes } \\
\text { No }\end{array}$ & $\begin{array}{l}326 \\
81\end{array}$ & $\begin{array}{l}80.0 \\
20.0\end{array}$ \\
\hline $\begin{array}{l}\text { Maintained follow-up } \\
\text { schedule }\end{array}$ & $\begin{array}{l}\text { Yes } \\
\text { No }\end{array}$ & $\begin{array}{l}301 \\
106\end{array}$ & $\begin{array}{l}74.0 \\
26.0\end{array}$ \\
\hline $\begin{array}{l}\text { Cleanness of waiting area and } \\
\text { toilet }\end{array}$ & $\begin{array}{l}\text { Yes } \\
\text { No }\end{array}$ & $\begin{array}{l}301 \\
106\end{array}$ & $\begin{array}{l}74.0 \\
26.0\end{array}$ \\
\hline $\begin{array}{l}\text { Willingness to visit and } \\
\text { recommend }\end{array}$ & $\begin{array}{l}\text { Yes } \\
\text { No }\end{array}$ & $\begin{array}{l}388 \\
19\end{array}$ & $\begin{array}{l}95.3 \\
4,7\end{array}$ \\
\hline
\end{tabular}

and above educational level. Clients who had low wealth index levels were 2.8 times [(AOR $=2.8,95 \% \mathrm{CI}$ : 1.27 , 6.28)] more likely to be satisfied than clients who had high wealth index levels (Table 3).

Related to the duration of staying on ART treatment, clients who had stayed on antiretroviral treatment more than 4 years were 2.7 times [( $\mathrm{AOR}=2.7,95 \% \mathrm{CI}: 1.46$, 5.20)] more likely to be satisfied than clients who had stayed on treatment less than 4 years. Waiting time, those participants seen by a health care provider less than 30 minutes were 5.4 times [( $\mathrm{AOR}=5.4,95 \% \mathrm{CI}: 2.52,11.57)]$ more likely to be satisfied compared with clients seen by health care providers more than 30 minutes (Table 3).
The odds of client satisfaction with ART services were more than three times [(AOR=3.7, 95\% CI: $1.59,8.49)$ ] more common among clients who disclose their HIV/ AIDS serostatus to their parents than clients who did not disclose their serostatus to their parents. Related to clients seen by the same health care providers, clients who had seen by the same health care providers were 2.0 times [(AOR $=2.0,95 \%$ CI: $1.06,3.82)]$ more likely to be satisfied compared to clients seen by different health care providers (Table 3).

Regarding loss of medical records, clients who were losing their medical records from the medical room during their follow-up visits were $74 \%$ [(AOR $=0.26,95 \% \mathrm{CI}$ : 0.13-0.50)] less likely to be satisfied than clients who not lost their medical records. Moreover, related to social supports, clients who had got social supports were 2.3 times [(AOR $=2.3,95 \% \mathrm{CI}: 1.12,4.63)]$ more likely to be satisfied than a client who did not have social supports (Table 3).

\section{Discussion}

In this study, the overall client satisfaction with antiretroviral therapy services was more than three-fourths $[76.9 \%$ (95\% CI: 72.7, 81.1)]. Regarding predictors, not attending formal and attending primary education, low wealth index levels, longer duration on ART treatment, shorter waiting time, disclosure of serostatus, seen by the same health care provider, loss of medical records, and social support were independent factors of client satisfaction with antiretroviral therapy services.

The overall client satisfaction with antiretroviral therapy services of this study is higher than studies conducted in South Africa $(52 \%)^{12}$ and in Ethiopia, Wollega $(57.6 \%),{ }^{14}$ Hosanna $(70.1 \%){ }^{15}$ and Tigray $(75.2 \%) .{ }^{19}$ The possible explanation for the higher than other studies might be due to the accessibility of good health care services and better health care coverage in the study area and the presence of different support giving stakeholders in the study area. Moreover, this might be due to sample size variation and transportation accessibility.

The finding of this study is lower than the studies conducted in Vietnam $(84.4 \%)^{9}$ and $(92.3 \%),{ }^{20}$ South Africa $(98 \%)^{21}$ and, $(93 \%),{ }^{22}$ Cameron $(91.2 \%),{ }^{23}$ Nigeria (99.6\%) (11) and Ethiopia in Tigray Region $(89.6 \%) .{ }^{13}$ The possible explanation for the lower than other studies might be due to the country having improved health care system and the socioeconomic status of the country. Moreover, they might have got support from 


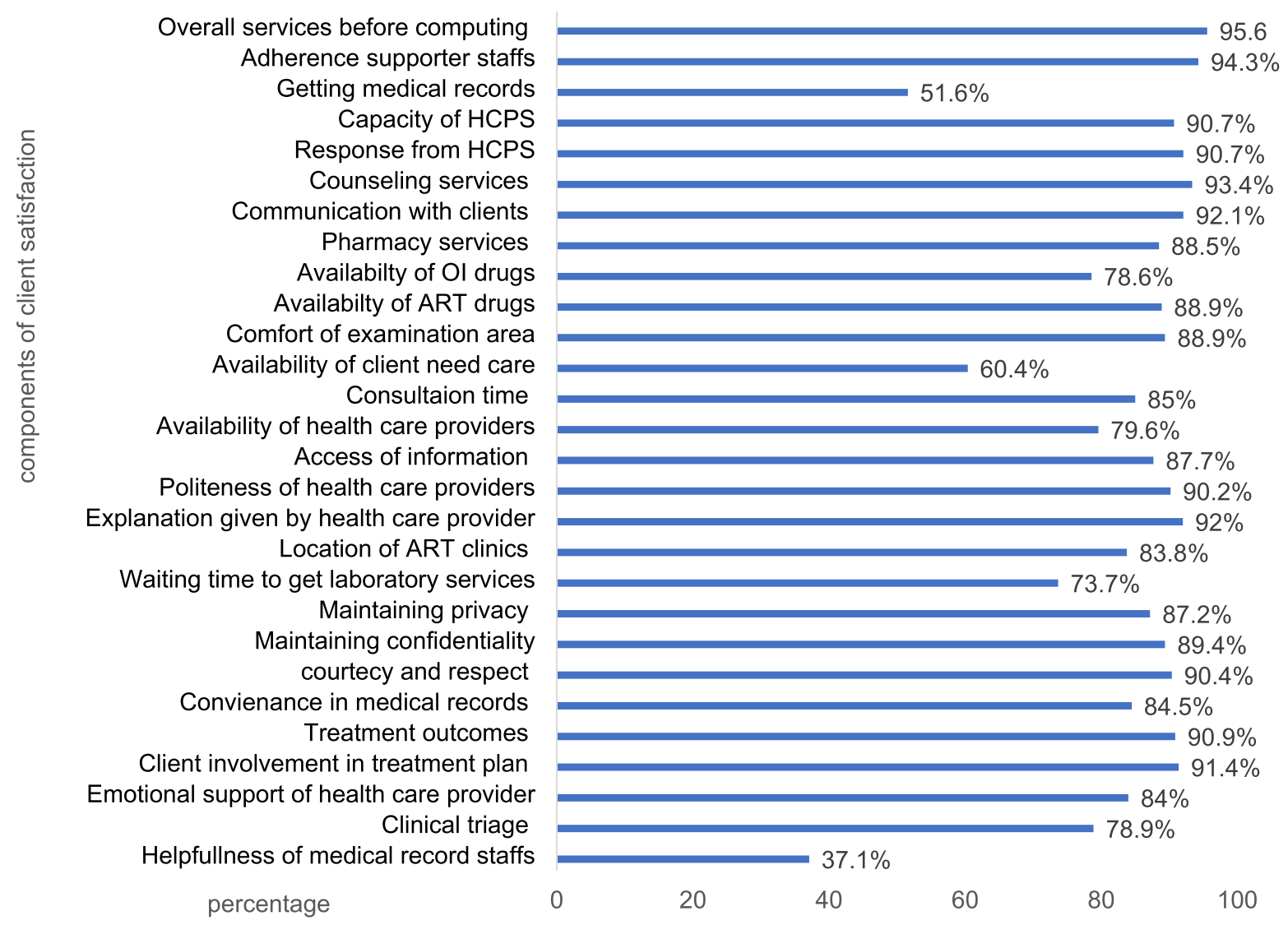

Figure I Magnitude of client satisfaction with major health care dimensions before computing together in public hospital, Harar Town, Eastern Ethiopia, 20I8 ( $=407$ ).

different non-governmental organizations which give invaluable improvements to service quality and client satisfaction towards ART services.

Clients who had not attended formal education and completed primary education were nearly four times more likely to be satisfied compared to those who had college and above educational level. This is consistent with studies conducted in Vietnam, ${ }^{9}$ Nigeria, ${ }^{24}$ South Africa, ${ }^{12}$ and Ethiopia Tigray Region. ${ }^{13}$ The possible reason in line with this study might be because clients who had not attended formal and completed primary education might have low expectations towards delivering ART services due to this might have more satisfied than clients who completed college and above educational level. Moreover, the clients are satisfied with the minimal service provisions they got from the health facilities and given more attention to counseling services which were delivered by health care providers during their follow-up visits.

Clients who had a low wealth index were approximately three times more likely to be satisfied when compared to high wealth index status. This is in line with the studies conducted in Vietnam. ${ }^{9,25}$ The possible reason might be because ART services are delivered free of charge and easily accessible for all clients who had ART follow-up in hospitals and health centers.

The odds of client satisfaction were widespread among clients staying on ART treatment for a longer duration. Clients who had stayed on ART more than 4 years were nearly three times more likely to be satisfied than clients who stayed on ART less than 4 years. However, the studies done in Nigeria by, ${ }^{11,24}$ and Kenya ${ }^{26}$ are inconsistent with this finding which stated that a shorter duration of ART treatment makes the client more satisfied than stays with a longer duration on ART treatment. The possible explanation might be clients who stayed on ART treatment a longer duration if they got access to important information, frequently counseled about the importance of ART services by health care providers and adherence supporters. In addition to this, the client might have a good understanding of the importance of ART services and may have good adherence to ART treatment, which leads to good treatment outcomes. Moreover, while the client stays on ART treatment, a longer duration might build trust and a good relationship with the health care 
Table 3 Bivariate and Multivariate Logistic Regression Analyses of Factors Associated with Client Satisfaction with Antiretroviral Therapy Services in Harar Town, 2018 ( $n=407)$

\begin{tabular}{|c|c|c|c|c|}
\hline Variables & Satisfied (\%) & Dissatisfied (\%) & COR $(95 \% \mathrm{Cl})$ & AOR $(95 \% \mathrm{Cl})$ \\
\hline \multicolumn{5}{|l|}{ Educational status } \\
\hline Not formal education & $49(60.5)$ & $32(39.5)$ & $0.8(0.33,2.32)$ & $3.7(I .75,8 . I I)^{* *}$ \\
\hline Primary education & $158(80.6)$ & $38(19.4)$ & $2.3(1.54-4.79)^{*}$ & $3.9(1.66,9.31)^{* *}$ \\
\hline Secondary education & $92(85.2)$ & $16(14.6)$ & $3.2(1.88-7.5 \mathrm{I})^{*}$ & $0.7(0.21,2.49)$ \\
\hline College and above & $14(63.6)$ & $8(36.4)$ & 1.00 & 1.00 \\
\hline \multicolumn{5}{|l|}{ Wealth index } \\
\hline Low & $102(8 \mathrm{I})$ & $24(19)$ & I.5 $(0.82,2.59)$ & $2.8(1.27,6.28)^{* *}$ \\
\hline Middle & $100(75.8)$ & $32(24.2)$ & I.I $(0.62, I .84)$ & $0.90(0.48,1.94)$ \\
\hline High & III (74.5) & $38(25.5)$ & 1.00 & 1.00 \\
\hline \multicolumn{5}{|c|}{ Duration on ART Rx } \\
\hline$\geq 4$ years & $163(86.7)$ & $25(13.5)$ & $2.9(1.80,4.98)$ & $2.7(1.46,5.20)^{* *}$ \\
\hline$<4$ years & $150(68.5)$ & $69(31.5)$ & 1.00 & 1.00 \\
\hline \multicolumn{5}{|l|}{ Waiting time } \\
\hline$<30$ minutes & $282(80.1)$ & $70(19.9)$ & $3.1(1.72,5.65)^{*}$ & $5.4(2.52,11.57)^{* *}$ \\
\hline$\geq 30$ minutes & $3 \mid(56.4)$ & $24(43.6)$ & 1.00 & 1.00 \\
\hline \multicolumn{5}{|c|}{ Disclosure of serostatus } \\
\hline Yes & $297(81.8)$ & $66(18.2)$ & $7.8(4.03,15.4)^{*}$ & $3.7(1.59,8.49)^{* *}$ \\
\hline No & $16(36.4)$ & $28(63.6)$ & 1.00 & 1.00 \\
\hline \multicolumn{5}{|c|}{ Seen by the same HCPs } \\
\hline Yes & $236(83.1)$ & $48(16.9)$ & $3.2(1.94,4.74)^{*}$ & $2.0(1.06,3.82)^{* *}$ \\
\hline No & $77(62.6)$ & $46(37.4)$ & 1.00 & 1.00 \\
\hline \multicolumn{5}{|c|}{ Loss of medical records } \\
\hline Yes & $123(68.3)$ & $57(31.7)$ & $0.42(0.26,0.67)^{*}$ & $0.26(0.16-0.56)^{* *}$ \\
\hline No & $190(83.7)$ & $37(16.3)$ & 1.00 & 1.00 \\
\hline \multicolumn{5}{|l|}{ Social support } \\
\hline Yes & $235(86.7)$ & $36(13.3)$ & $4.8(1.94,5.10)^{*}$ & $2.3(1.12,4.63)^{* *}$ \\
\hline No & $78(57.4)$ & $58(42.6)$ & 1.00 & 1.00 \\
\hline \multicolumn{5}{|l|}{ Maintained follow-up } \\
\hline Yes & $234(81.5)$ & $53(18.5)$ & $2.3(1.42-3.71)^{*}$ & I.I $(0.52,1.98)$ \\
\hline No & $79(65.8)$ & $4 I(34.2)$ & 1.00 & 1.00 \\
\hline
\end{tabular}

Notes: *p-value $<0.005$, **p-value $<0.001$.

Abbreviations: COR, crude odds ratio; AOR, adjusted odds ratio.

providers as well as with hospital staff since clients will be more satisfied with the delivered ART services.

Another important predictor of client satisfaction is waiting time. Clients seen by health care providers for less than 30 minutes were more than five times more likely to be satisfied than clients seen greater than 30 minutes.
This is consistent with the studies conducted in Vietnam, ${ }^{25}$ Nigeria, ${ }^{24}$ and Ethiopia Tigray Region. ${ }^{13}$ The possible explanation might be due to avoid unnecessary wasting of their time in the health facilities and the client might get more time to perform their daily activities in their workplace. Moreover, clients are not bored with the hospital 
environment because might be more satisfied if they get the necessary ART services on time.

The odds of client satisfaction with ART services were more common among clients who had disclosed their zero status to their parents. Clients who disclosed their serostatus of HIV/AIDS to their parents were nearly three times more likely to be satisfied when compared to clients who does not disclose their serostatus to their parents. This is consistent with the study conducted in the Southern part of Ethiopia, Hosanna. ${ }^{14}$ The probable explanation might be that clients who disclose their serostatus can freely discuss their treatment with their parents and others. In addition to this, clients might get supports from their parents and different support-giving organizations. Moreover, they might develop a good relationship with their family members and others due to they might be more satisfied with the delivered ART services from the hospital ART clinics.

The odds of client satisfaction were more common among clients who had been seen by the same health care providers. Clients who had been seen by the same health care providers were twofold more likely to be satisfied than clients seen by different health care providers. The possible explanation might be that clients who have been seen by the same health care providers will build trust with the health care provider and develop a strong relationship with them. In addition to this, it might create a conducive working environment and freely discuss what they fill without any fear. Moreover, when the client and health care provider stay with gather for a longer duration might be addressed to their health problems due to this client more satisfied with the delivered ART services.

Regarding medical records, clients who had lost their medical records were $74 \%$ less likely to be satisfied than clients who did not lose their medical records during their follow-up visits. The possible reason might be because clients get their medical records during follow-up visits, did not waste their time to get ART services, and did not create conflict with medical record room staffs, so that they might have a good relationship with medical record staffs and with health care providers because clients were more satisfied with the delivered ART services. In addition to this, the probability of missing their ART drug will be low and might have good health outcomes.

Related to social support, clients who got social supports from their families and other non-governmental organizations were more than two times more likely to be satisfied than clients who had not got social support.
This study is consistent with the study conducted in Nigeria by. ${ }^{26}$ The possible reason might be due to getting social supports that address their social problems which are incapable to solve by themselves. In addition to this, the client who had social support might have a good understanding of ART services. Moreover, clients who had got social support from support giving organizations like nutritional, economic, spiritual, and legal supports might solve their immediate problem since clients might be satisfied more with ART services delivered in the hospital ART clinics.

Generally, this study tried to assess client satisfaction with antiretroviral therapy services and factors associated with client satisfaction with ART services, and it can be an input for health facilities to provide client-centered health care services.

Even if the findings of this study indicate relatively high magnitude of client satisfaction (76.9\%) with ART services, the government of Ethiopia including local governmental and non-governmental stakeholders should pay more attention to provide more innovative and clientcentered health care services, to achieve the remaining $25 \%$ of dissatisfaction. Therefore, the government of Ethiopia, particularly the public hospitals in Harar Town, should be prioritizing, planning, designing and initiating ART services intervention programs aimed at improving the service satisfactions of the clients.

Regarding the strength and limitations of the study, data were collected from the client immediately before leaving the compound of the hospital, which helps clients to clearly remember about the delivered ART services to be asked and used to minimize recall bias. However, the study might have faced some limitations, such as generalization to the overall health facilities in Harar Town was not possible because the data collection was restricted to clients found in public hospitals of the Harar Town. Since the interview has occurred within the hospital setting, study subjects might refrain to express their dissatisfaction, which leads to social desirability bias, and it is difficult to know the accurate value of each five measurement scale effects. Moreover, there is also limited related literature, especially for some variables like loss of medical records and clients seen by the same health care providers.

\section{Conclusion}

In conclusion, the percentage of clients who expressed satisfaction with HIV treatment services at the Harar 
public Hospital was relatively low. There was a relationship between client satisfaction with educational status, wealth index, longer duration of ART treatment, shorter waiting time, disclosure of serostatus, seen by the same health care provider, loss of medical records, and social supports.

\section{Data Sharing Statement}

The data used to support the findings of this study are available from the corresponding author upon reasonable request.

\section{Acknowledgments}

My special thanks and sincere appreciation go to Haramaya University for the approval of the ethical clearance and my advisors for their technical support of this study. I would also like to acknowledge study participants, supervisors, data collectors, and data clerks for their tremendous role throughout the study.

\section{Author Contributions}

All authors (TM, YD, BG, ZB, GA, and LG) contributed to data analysis, drafting or revising the article, have agreed on the journal to which the article will be submitted, gave final approval of the version to be published, and agree to be accountable for all aspects of the work.

\section{Funding}

There is no funding body for this study. This manuscript was prepared from the thesis work of Mr Taye Mekonnen, who covered the cost of conducting this research.

\section{Disclosure}

The authors report no conflicts of interest in this work.

\section{References}

1. Kagashe G, Rwebangila F. Patient satisfaction with health care services provided at HIV clinics at Amana and Muhimbili Hospitals in Dar es Salaam. Afr Health Sci. 2011;11(3):60-66. doi:10.4314/ahs. v11i3.70072

2. Vinagre MH, Neves J. The influence of service quality and patients' emotions on satisfaction. Int J Health Care Qual Assur. 2008;21 (1):87-103. doi:10.1108/09526860810841183

3. Carly E. Effect of patient satisfaction with a health care facility on HIV outcomes: a facility-level study in eastern Africa. 2014.

4. Nabbuye-Sekandi J, Makumbi FE, Kasangaki A. Patient satisfaction with services in outpatient clinics at Mulago hospital, Uganda. Int J Qual Health Care. 2011;23:516-523. doi:10.1093/intqhe/mzr040

5. Yang Y, Shyh JL, Miles M. How and when service quality and satisfaction simultaneously influence purchase intentions. Health Serv Manag Res. 2011.
6. Reda AA, Biadgilign S. Determinants of adherence to antiretroviral therapy among HIV infected patients in Africa. AIDS Res Treat. 2012.

7. Kwesiga D. A comparative analysis of client satisfaction among people receiving HIV/AIDS care from public and private health facilities in Kabale district, Uganda. 2010.

8. WHO. Global Action Plan Report on HIV Drug Resistance from 2017-2021. WHO; 2018.

9. Bach X, Nhung P. Patient satisfaction with HIV/AIDS care and treatment in the decentralization of services delivery in Vietnam. PLoS One. 2012;7(10).

10. Syed A, Ashvinni R, Keivan A, Syed S, Christopher K. Evaluation of patient satisfaction with HIV/aids care and treatment: a cross-sectional stud. Person Center Healthc. 2017;5(1).

11. Okafoagu N, Ango JT, Gana G, et al. Clients' satisfaction with antiretroviral therapy services in a tertiary hospital in Sokoto, Nigeria. J AIDS HIV Res. 2013;5(9):328-333.

12. Natsayi CH, Till B, Marie L. Patient satisfaction with HIV and TB treatment in a public program in rural KwaZulu-Natal: evidence from patient-exit interviews. BMC Health Serv Res. 2014;14(32).

13. Tessema SB, Adane MM. Assessment of antiretroviral treatment (ART) care service provision in Tigray Region health centers, North Ethiopia. BMC Health Serv Res. 2015;15(368).

14. Ashenafi H, Yibeltal K, Client E,Y. Satisfaction and its determinants with Anti- Retroviral Therapy (ART) services in public hospitals of West Wollega Zone, Ethiopia. Galore Int J Appl Sci Human. 2017;1(1).

15. Doyore F, Moges B. Client satisfaction to antiretroviral treatment services and associated factors among clients attending ART clinics in Hossana Town, Southern Ethiopia. Clin Res Trials. 2016;2(6).

16. Tayelgn A, Desalegn T, Kebede Y. Mothers'satisfaction with referral hospital delivery service in Amhara Region, Ethiopia. $B M C$ Pregnancy Childbirth. 2011;11(1). doi:10.1186/1471-2393-11-78

17. FMOH (Federal Ministry of Health). Federal Democratic Republic of Ethiopia growth and transformation plan II (GTP II) (2015/16-2019/ 20) health sector development program IV in line with GTP 2010/112014/15. Addis Ababa; 2015. Available from: http://www.ausaid.gov. au/...esign-summary-imp-doc.doc. Accessed November 17, 2018.

18. Bitew K, Ayichiluhm M, Yimam K. Maternal satisfaction on delivery service and its associated factors among mothers who gave birth in public health facilities of Debre Markos Town, Northwest Ethiopia. Biomed Res Int. 2015;2015:1-6. doi:10.1155/2015/460767

19. Kiflay G, Daniel A. High antiretroviral therapy service delivery satisfaction and its associated factors at Midre-genet hospital; Northwest Tigray, Ethiopia. BMC Health Serv Res. 2018;8:223. doi:10.1186/s12913-018-3055-4

20. Bhagat V, Pal DK, Rama L, Vishal B. Clients satisfaction with anti retroviral therapy services at Hamidia Hospital Bhopal. Natl J Commun Med. 2011;2(2).

21. Bezuidenhout S, Ogunsanwo DA, Helberg EA. Patient satisfaction at accredited antiretroviral treatment sites in the Gert Sibande District. Afri J Prim Health Care Fam Med. 2014;6. doi:10.4102/phcfm. v6i1.627.

22. Muhammad H, Hendry V. ART patients' satisfaction level regarding comprehensive HIV and AIDS care management and antiretroviral treatment. Epidemiol Infect. 2012.

23. Buh A, Peter NF, Atashili J. Clients' satisfaction with HIV treatment services in Bamenda, Cameroon. BMC Health Serv Res. 2016;16 (280).

24. Osungbade KO, Shaahu VN, Owoaje EE, Adedokun BO. Patients' satisfaction with quality of anti-retroviral services in Central Nigeria: implications for strengthening private health services. Prev Med. 2013;1(3):11-18.

25. Tran BX, Nguyen LH, Phan HT, Latkin CA. Patient satisfaction with methadone maintenance treatment in Vietnam: a comparison of different integrative-service delivery. Plos One. 2015;10(11):10.1371. 
26. Obinna $\mathrm{O}$, Ifeanyi $\mathrm{C}$, Chinyere $\mathrm{M}$, Chiegil $\mathrm{R}$, Kwasi $\mathrm{T}$. Investigating client perception and attitude to decentralization of HIV/AIDS treatment services to primary health centers in three Nigerian states. Health Expect. 2016.
27. World Medical Association Declaration of Helsinki. Ethical principles for medical research involving human subjects. Adopted by the 18th WMA General Assembly, Helsinki, Finland, June 1964. Bull World Health Organ. 2001;79(4).

HIV/AIDS - Research and Palliative Care

\section{Publish your work in this journal}

HIV/AIDS - Research and Palliative Care is an international, peerreviewed open-access journal focusing on advances in research in HIV, its clinical progression and management options including antiviral treatment, palliative care and public healthcare policies to control viral spread. The manuscript management system is completely online and includes a very quick and fair peer-review system, which is all easy to use. Visit http://www.dovepress.com/testimonials.php to read real quotes from published authors. 